\title{
Prevalensi Polip Kolorektal di RSUD Tarakan Tahun 2010-2016
}

\author{
Shintia Christina ${ }^{1}$, Mawar Makmaker ${ }^{2}$ \\ ${ }^{1}$ Departemen Patologi Anatomi Fakultas Kedokteran dan Ilmu Kesehatan \\ Universitas Kristen Krida Wacana \\ ${ }^{2}$ Fakultas Kedokteran dan Ilmu Kesehatan Universitas Kristen Krida Wacana \\ Alamat Korespondensi: shintiatc@gmail.com
}

\begin{abstract}
Abstrak
Kejadian polip kolorektal akan meningkat seiring dengan bertambahnya usia. Berdasarkan kriteria World Health Organization (WHO), polip kolorektal dibagi menjadi adenoma, serrated dan hamartoma. Tujuan penelitian ini adalah untuk mengetahui prevalensi polip kolorektal berdasarkan umur, jenis kelamin, lokasi, dan jenis polipnya di RSUD Tarakan Jakarta Pusat dari Januari 2010 hingga Oktober 2016. Desain penelitian dalam penelitian ini adalah deskriptif dengan jenis studi potong lintang. Teknik pengambilan sampling menggunakan total sampel. Data yang diambil berdasarkan data sekunder dari bagian Patologi Anatomi. Total sampel yang didapatkan ada 51 kasus. Hasil penelitian menunjukkan angka persentase polip kolorektal pada laki laki sebesar 60,8\% dan pada perempuan sebesar 39,2\% Angka prevalensi polip kolorektal pada usia 51-60 tahun sebesar 35,3\%. Lokasi polip kolorektal pada rektum didapatkan sebesar $41,2 \%$. Jenis polip yang ditemukan adalah polip inflamatorik sebesar $47,1 \%$, diikuti polip adenoma $39,1 \%$. Pada polip adenoma didapati adenoma tubulo-villosum displasia keras 17,6\%, adenoma tubular displasia keras $7,8 \%$ dan adenoma tubular displasia rendah 13,7\%. Kejadian polip kolorektal akan meningkat pada usia >50 tahun dan lebih banyak terjadi pada laki-laki. Lokasi terbanyak kejadian polip kolorektal adalah pada rektum. Jenis polip yang sering terjadi adalah polip inflamatorik.
\end{abstract}

Kata Kunci: kolorektal, polip, prevalensi, patologi.

\section{Prevalence of Colorectal Polyp at Tarakan Hospital}

\begin{abstract}
Incidence of colorectal polyp increases with patient age. Based on the criteria from World Health Organization (WHO), colorectal polyp can be classified into adenoma, serrated and hamartoma. The purpose of this study is to evaluate the prevalence of colorectal polyp at RSUD Tarakan Central Jakarta, based on age, sex, location and polyp type. This cross-sectional study used secondary data from the anatomical pathology department from January 2010 to October 2016. Fifty-one samples were obtained. The incidence of colorectal polyp found in men and women were $60.8 \%$ and $39.2 \%$, respectively. Of the total samples, $35.3 \%$ patients were 51 to 60 years of age. The majority of colorectal polyp was located in the rectum (41.2\%). The most common colorectal polyp found were inflammatoric polyps (47.1\%), followed by adenoma polyp (39.1\%). Among adenoma polyps, there were tubule villous adenoma with severe dysplasia (17.6\%), tubular adenoma with severe dysplasia (7.8\%) and tubular adenoma with mild dysplasia (13.7\%). The study found more colorectal polyp in people above 50 years old and among men. The colorectal polyp most frequently found was inflammatoric polyp.
\end{abstract}

Keywords: colorectal, polyp, prevalence, pathology 


\section{Pendahuluan}

Polip kolorektal adalah pertumbuhan lambat mukosa kolon dan rektum ke arah lumen yang berisiko menjadi ganas. ${ }^{1}$ Polip kolorektal tidak dapat dibedakan secara makroskopik, sehingga dibutuhkan pemeriksaan histopatologis untuk memastikan jenis polip. Polip kolorektal tidak semuanya berpotensi menjadi ganas. Polip adenoma memiliki sifat neoplastik. Jenis lainnya tidak berpotensi menjadi ganas seperti polip hiperplastik, hamartoma dan polip inflamatorik. ${ }^{2,3}$ Klasifikasi polip kolorektal berdasarkan World Health Organization (WHO) berbeda, yaitu adenoma, serrated dan hamartoma. ${ }^{2,3}$

Berdasarkan data dari pusat endoskopi Cipto Mangunkusumo Jakarta, Indonesia, Julwan dkk pada tahun 2007 melaporkan dari 662 pasien yang menjalani pemeriksaan kolonoskopi sebesar 23,2\% diantaranya didapatkan polip dan kanker kolorektal. ${ }^{4}$ Hornick dkk pada tahun 2009 melakukan penelitian dengan sampel sebanyak 1.050 polip kolon. ${ }^{5}$ Di antara sampel tersebut didapatkan $82 \%$ adalah adenoma, $12 \%$ hiperplastik, 3\% inflamatorik, dan $1,5 \%$ adalah polip mesenkimal yaitu lipoma dan leiomioma. ${ }^{5}$

Kejadian polip kolon cukup sering dan insidennya meningkat seiring dengan bertambahnya usia. Polip kolorektal umumnya terjadi pada individu yang lebih dari 50 tahun. ${ }^{6}$ Penelitian pada populasi usia $<50$ tahun menunjukkan prevalensi $12 \%$ pada perempuan dan $24 \%$ pada laki-laki menderita adenoma, sedangkan pada populasi usia > 80 tahun didapatkan prevalensi $27 \%$ pada perempuan dan prevalensi $40 \%$ pada laki-laki. ${ }^{2}$

Pemeriksaan histopatologis penting dilakukan pada setiap kasus polip, karena jenis polip tidak dapat dibedakan secara klinis. ${ }^{7}$ Potensi menjadi ganas yang berbeda, sehingga pemeriksaan histopatologi sangat mempengaruhi prognosis pasien. ${ }^{7}$ Adenoma kolorektal merupakan prekursor terjadinya kanker kolorektal, terutama melalui jalur microsatellite instable. ${ }^{8}$

\section{Metodologi Penelitian}

\section{Subjek Penelitian}

Subjek dalam penelitian ini adalah semua pasien yang terdiagnosis polip kolorektal dalam rentang waktu Januari 2010 sampai Oktober 2016 di RSUD Tarakan Jakarta
Pusat berdasarkan klasifikasi WHO 2010 dan pada formulir patologi anatomi dicantumkan dengan jelas kesimpulan akhir hasil pemeriksaannya. Total sampel dalam penelitian ini sebanyak 55 sampel. Sampel yang memenuhi kriteria inklusi sebanyak 51 kasus.

\section{Kaji etik}

Penelitian ini dinyatakan telah lolos kaji etik dengan nomor 004/SLKEIM/UKKW/FK/KE/IX/2016 dari Komite Etik Fakultas Kedokteran dan Ilmu Kesehatan Universitas Kristen Krida Wacana.

\section{Analisis Data}

Semua data yang telah dikumpulkan, dicatat, dikelompokkan, diolah dan kemudian ditampilkan dalam bentuk tabel sesuai dengan tujuan penelitian yaitu untuk mengetahui prevalensi polip kolorektal di RSUD Tarakan selama Januari 2010 hingga Oktober 2015. Pengolahan data dilakukan menggunakan program SPSS 16.

\section{Hasil Penelitian}

Dari 51 kasus didapatkan persentase polip kolorektal pada laki laki lebih besar yaitu $60,8 \%$ dan $39,2 \%$ pada perempuan. Jenis polip kolorektal dengan persentase terbesar pada laki-laki adalah polip inflamatorik yaitu 31,4\% dan pada perempuan jenis polip dengan persentase terbesar juga polip inflamatorik yaitu $47,1 \%$.

Jenis polip yang paling banyak di temukan pada penelitian ini adalah polip inflamatorik yaitu $47,1 \%$, diikuti dengan polip adenoma $39,1 \%$. Pada polip adenoma didapatikan adenoma tubulo-villosum displasia keras $17,6 \%$, adenoma tubular displasia keras $7,8 \%$ dan adenoma tubular displasia ringan sebesar $13,7 \%$.

Prevalensi terbesar terjadi polip kolorektal adalah pada usia 51-60 tahun yaitu sebesar 35,3\%. Pada usia 51-60 tahun paling banyak ditemukan polip kolorektal jenis adenoma yaitu sebesar 19,6\%, baik adenoma tubular dan adenoma tubulo-villosum. Lima kasus polip juvenile ditemukan 4 kasus pada usia 0-10 tahun dan 1 kasus pada usia 41-50 tahun tepatnya 41 tahun. Polip juvenile biasanya ditemukan pada anak-anak, namun tidak menutup kemungkinan juga dapat ditemukan pada dewasa. 
Lokasi polip kolorektal tersering yang didapatkan pada penelitian adalah di rectum, sebesar 41,2\%. Jenis polip kolorektal terbanyak di rektum adalah polip inflamatorik sebesar
11,8\%. Pada lima kasus didapati polip kolorektal terdapat pada lebih dari 1 lokasi dengan dua adenoma tubular displasia ringan dan tiga kasus polip inflamatorik.

Tabel 1. Jenis Polip Kolorektal Berdasarkan Jenis Kelamin dan Frekuensinya

\begin{tabular}{lcccccc}
\hline \multicolumn{1}{c}{ Jenis polip } & $\begin{array}{c}\text { Laki- } \\
\text { laki (n) }\end{array}$ & $\begin{array}{c}\text { Laki- } \\
\text { laki }(\boldsymbol{\%})\end{array}$ & $\begin{array}{c}\text { Perempuan } \\
(\mathbf{n})\end{array}$ & $\begin{array}{c}\text { Perempuan } \\
(\boldsymbol{\%})\end{array}$ & Total & $\begin{array}{c}\text { Total } \\
(\%)\end{array}$ \\
\hline Adenoma tubular displasia keras & 3 & 5,9 & 1 & 2,0 & 4 & 7,8 \\
Adenoma tubular displasia ringan & 4 & 7,8 & 3 & 5,9 & 7 & 13,7 \\
Polip inflamatorik & 16 & 31,4 & 8 & 15,7 & 24 & 47,1 \\
Polip hiperplastik & 1 & 2,0 & 0 & 0,0 & 1 & 2,0 \\
$\begin{array}{l}\text { Adenoma tubulo-villosum } \\
\text { displasia keras }\end{array}$ & 4 & 7,8 & 5 & 9,8 & 9 & 17,6 \\
Polip serreted displasia ringan & 1 & 2,0 & 0 & 0,0 & 1 & 2,0 \\
Polip juvenile & 2 & 3,9 & 3 & 5,9 & 5 & 9,8 \\
$\begin{array}{l}\text { Adenoma tubulo-villosum } \\
\text { displasia ringan }\end{array}$ & 0 & 0,0 & 0 & 0,0 & 0 & 0 \\
Total & 31 & 60,8 & 20 & 39,2 & 51 & 100 \\
\hline
\end{tabular}

Tabel 2. Jenis Polip Kolorektal Berdasarkan Umur dan Frekuensinya

\begin{tabular}{|c|c|c|c|c|c|c|c|c|c|}
\hline Umur & $\begin{array}{l}\text { Adenoma } \\
\text { tubular } \\
\text { displasia } \\
\text { keras }\end{array}$ & $\begin{array}{l}\text { Adenoma } \\
\text { tubular } \\
\text { displasia } \\
\text { ringan }\end{array}$ & $\begin{array}{l}\text { Polip } \\
\text { inflama-torik }\end{array}$ & $\begin{array}{l}\text { Polip } \\
\text { hiperplasti } \\
\text { k }\end{array}$ & $\begin{array}{l}\text { Adeno } \\
\text { tubulo- } \\
\text { villosum } \\
\text { displasia } \\
\text { keras }\end{array}$ & $\begin{array}{l}\text { Polip } \\
\text { serreted } \\
\text { displa-sia } \\
\text { ringan }\end{array}$ & $\begin{array}{l}\text { Polip } \\
\text { juvenile }\end{array}$ & $\begin{array}{l}\text { Adenoma } \\
\text { tubulo-villo- } \\
\text { sum displa- } \\
\text { sia ringan }\end{array}$ & Total \\
\hline $0-10$ & 0 & 0 & 0 & 0 & 0 & 0 & $4(7,8 \%)$ & 0 & $4(7,8 \%)$ \\
\hline $11-20$ & 0 & $1(2 \%)$ & $1(2 \%)$ & 0 & 0 & 0 & 0 & 0 & $2(3,9 \%)$ \\
\hline $21-30$ & 0 & 0 & $3(5,9 \%)$ & 0 & 0 & 0 & 0 & 0 & $3(5,9 \%)$ \\
\hline $31-40$ & 0 & 0 & $7(13,7 \%)$ & 0 & 0 & $1(2 \%)$ & 0 & 0 & $8(15,7 \%)$ \\
\hline $41-50$ & 0 & 0 & $4(7,8 \%)$ & 0 & $3(5,9 \%)$ & 0 & $1(2 \%)$ & 0 & $8(15,7 \%)$ \\
\hline $51-60$ & $4(7,8 \%)$ & $3(5,9 \%)$ & $8(15,7 \%)$ & 0 & $3(5.9 \%)$ & 0 & 0 & 0 & $18(35,3 \%)$ \\
\hline $61-70$ & 0 & $1(2 \%)$ & $1(2 \%)$ & $1(2 \%)$ & $1(2 \%)$ & 0 & 0 & 0 & $4(7,9 \%)$ \\
\hline $71-80$ & 0 & $2(3,9 \%)$ & 0 & 0 & $1(2 \%)$ & 0 & 0 & 0 & $3(5,9 \%)$ \\
\hline $\begin{array}{l}\text { Tidak } \\
\text { ada }\end{array}$ & 0 & 0 & 0 & 0 & $1(2 \%)$ & 0 & 0 & 0 & $1(2 \%)$ \\
\hline
\end{tabular}

\section{Pembahasan}

Hasil penelitian dengan dari total 51 kasus diketahui bahwa persentase polip kolorektal pada laki laki lebih besar yakni $60,8 \%$ dan pada perempuan sebesar 39,2\%. Hal ini sesuai dengan penelitian yang dilakukan oleh Khan dkk pada tahun 1998., ${ }^{9,10,11}$ Hasil penelitian juga sejalan dengan penelitian di Turki dengan 3514 sampel, $470 \quad(13,3 \%)$ dimana sampel terbanyak dilakukan polipektomi didapatkan pada laki-laki $(61,7 \%)$ dengan $66,4 \%$ sampel berusia diatas 50 tahun. ${ }^{12}$ Pada kelompok polip adenoma, penderita polip diatas usia 50 tahun adalah $71,8 \%$ dan yang menderita polip adenoma sebanyak $63,9 \%{ }^{12}$ 
Tabel 3. Jenis Polip Kolorektal Berdasarkan Lokasi dan Frekuensinya

\begin{tabular}{|c|c|c|c|c|c|c|c|c|c|}
\hline Lokasi & $\begin{array}{l}\text { Adenoma } \\
\text { tubular } \\
\text { displasia } \\
\text { keras }\end{array}$ & $\begin{array}{l}\text { Adenoma } \\
\text { tubular } \\
\text { displasia } \\
\text { ringan }\end{array}$ & $\begin{array}{l}\text { Polip } \\
\text { inflamato } \\
\text {-rik }\end{array}$ & $\begin{array}{l}\text { Polip } \\
\text { hiperpla } \\
\text { stik }\end{array}$ & $\begin{array}{l}\text { Adenoma } \\
\text { tubulo- } \\
\text { villosum } \\
\text { displasia } \\
\text { keras } \\
\end{array}$ & $\begin{array}{l}\text { Polip } \\
\text { serreted } \\
\text { displasia } \\
\text { ringan }\end{array}$ & $\begin{array}{l}\text { Polip } \\
\text { juve-nile }\end{array}$ & $\begin{array}{l}\text { Adenoma } \\
\text { tubulo- } \\
\text { villosum } \\
\text { displasia } \\
\text { ringan } \\
\end{array}$ & Total \\
\hline \multicolumn{10}{|l|}{ Satu Lokasi } \\
\hline $\begin{array}{l}\text { Kolon } \\
\text { ascenden }\end{array}$ & 0 & 0 & $5(9,8 \%)$ & 0 & $2(3,9 \%)$ & 0 & 0 & 0 & $7(13,7 \%)$ \\
\hline $\begin{array}{l}\text { Kolon } \\
\text { desenden }\end{array}$ & 0 & 0 & 0 & 0 & 0 & 0 & 0 & 0 & 0 \\
\hline $\begin{array}{l}\text { Kolon } \\
\text { transversum }\end{array}$ & 0 & 0 & 0 & 0 & 0 & 0 & 0 & 0 & 0 \\
\hline Sigmoid & $1(2 \%)$ & $1(2 \%)$ & $2(3,9 \%)$ & 0 & $1(2 \%)$ & 0 & 0 & 0 & $5(9,8 \%)$ \\
\hline Sekum & 0 & $2(3,9 \%)$ & $1(2 \%)$ & 0 & 0 & 0 & 0 & 0 & $3(5,9)$ \\
\hline Rektum & $3(5,9 \%)$ & $1(2 \%)$ & $6(11,8 \%)$ & $1(2 \%)$ & $4(7,8 \%)$ & $1(2 \%)$ & $5(9,8 \%)$ & 0 & $21(41,2 \%)$ \\
\hline Kolon & 0 & 0 & $7(13,7 \%)$ & 0 & $2(3,9 \%)$ & 0 & 0 & 0 & $9(17,6 \%)$ \\
\hline $\begin{array}{l}\text { Tidak } \\
\text { tercantum }\end{array}$ & 0 & $1(2 \%)$ & 0 & 0 & 0 & 0 & 0 & 0 & $1(2 \%)$ \\
\hline \multicolumn{10}{|l|}{ >1 lokasi } \\
\hline $\begin{array}{l}\text { Kolon } \\
\text { ascenden, } \\
\text { sigmoid, } \\
\text { Rektum. }\end{array}$ & 0 & $1(2 \%)$ & 0 & 0 & 0 & 0 & 0 & 0 & 1 \\
\hline $\begin{array}{l}\text { Kolon } \\
\text { ascenden, } \\
\text { caecum. }\end{array}$ & 0 & 0 & $1(2 \%)$ & 0 & 0 & 0 & 0 & 0 & 1 \\
\hline $\begin{array}{l}\text { Rekto- } \\
\text { sigmoid, } \\
\text { kolon } \\
\text { descenden. }\end{array}$ & 0 & $1(2 \%)$ & 0 & 0 & 0 & 0 & 0 & 0 & 1 \\
\hline $\begin{array}{l}\text { Rektum, } \\
\text { sigmoid. }\end{array}$ & 0 & 0 & $1(2 \%)$ & 0 & 0 & 0 & 0 & 0 & 1 \\
\hline $\begin{array}{l}\text { Sigmoid, } \\
\text { kolon } \\
\text { transversum }\end{array}$ & 0 & 0 & $1(2 \%)$ & 0 & 0 & 0 & 0 & 0 & 1 \\
\hline
\end{tabular}

Pada penelitian ini didapatkan jenis polip terbanyak adalah polip inflamatorik $(47,1 \%)$. Hal ini tidak sesuai dengan hasil penelitian lain dimana jenis yang terbanyak adalah adenoma. ${ }^{12-}$ ${ }^{14} \mathrm{Hal}$ ini dapat disebabkan oleh sebaran usia pasien yang beragam dari usia dibawah 10 tahun hingga 80 tahun, namun pada usia 51-60 tahun paling banyak ditemukan jenis adenoma yaitu sebesar $19,6 \%$, dibandingkan dengan polip inflamatorik yang hanya $15,7 \%$.

Prevalensi terbesar terjadi polip kolorektal adalah pada rentang usia 51-60 tahun yaitu sebesar 35,3\%. Hasil penelitian ini sejalan dengan beberapa penelitian lain, yaitu polip kolorektal lebih banyak terjadi pada usia lebih dari 50 tahun. ${ }^{1,9-13 .}$ Lokasi polip kolorektal tersering yang didapatkan pada penelitian adalah di rektum, yakni sebesar $41,2 \%$. Hal tersebut sejalan dengan berbagai penelitian lainnya dengan hasil serupa. ${ }^{14-16}$ Meski ada penelitian lain dengan hasil berbeda dengan persentase karsinoma paling banyak ditemukan di kolon descenden proksimal. ${ }^{17}$ Penelitian lain menunjukkan bahwa lokasi polip 54\% di kolon kanan dan $46 \%$ di kolon kiri. ${ }^{18-20}$ Dari hasil penelitian yang bertolak belakang tersebut menunjukkan pentingnya pemeriksaan kolonoskopi secara menyeluruh dan lengkap, tanpa ada bagian yang terlewatkan

\section{Simpulan}

Pada penelitian ini polip kolorektal didapatkan lebih banyak pada laki-laki $(60,8 \%)$. Usia yang paling sering terkena adalah usia 5160 tahun (35,3\%). Lokasi paling sering di rektum $(41,2 \%)$ dan jenis polip yang terbanyak adalah polip inflamatorik $(47,1 \%)$.

\section{Daftar Pustaka}

1. Abdullah M, Firmansyah M. Pendekatan terkini polip kolon. Dalam: Setiati S, Sudoyo AW, Setiyohadi B, Simadibrata M, Syam AF, editor. Buku ajar ilmu penyakit dalam. Edisi VI. Jakarta: Pusat Penerbitan Departemen Ilmu Penyakit 
Dalam Fakultas Kedokteran Universitas Indonesia: 2014.hal.1838-50.

2. Shussman N, Wexner S.D. Colorectal polyps and polyposis syndromes. Gastroenterol Rep. 2014:1-15.

3. Hamilton SR, Bosman FT, Boffetta P, et al. Carcinoma of the colon rectum. In: WHO classification of tumours of the digestive system. Ed: Bosman FT, Carneiro F, Hruban RH, Theise ND. $4^{\text {th }}$ edition. Internation agency on research of cancer. Lyon. 2010. France. p.133, 139-40.

4. Pribadi J, Abdullah M, Simadibrata M et al. Colorectal neoplasm in symptomatic Indonesian population: result of the colonoscopy examination. Gastroenterol hepatol. 2008; S(5):23-5.

5. Hornick JL, Odze RD. Polyps of the large intestine. In: Odze RD, Goldblum JR, editors. Surgical pathology of GI tract, liver, biliary tract and pancreas. Second Ed.Philadelphia: Saunders. 2009.

6. Santoro M. Colon polyps. [diunduh 5 Mar 2016]. Tersedia dari: http://www .medicinenet.com/script/main/art.asp?artic lekey $=7761$.

7. Korbar B, Olofson AM, Miraflor AP, et al. Deep learning for classification of colorectal polyps on whole-slide images. J Pathol Inform. 2017:1-8.

8. Fu Z, Shrubsole MJ, Smalley WE, et al. Lifestyle factors and their combined impact on the risk of colorectal polyps. Am J epid. 2012:766-76.

9. Kahn HS, Tatham LM, Thun MJ, Heath CW. Risk factors for self reported colon polyps. J Gen Intern Med. 1998;13:303-10.

10. Schulmann K, Pox C, Tannaefel A, Schmiegel W. The patient with multiple intestinal polyps. Best Pract Res Clin Gastroenterol. 2007;21:409-26.

11. Sudoyo AW, Lesmana R, Krisnuhoni E, Pakasi L, Cahyadinata L, Lesmana L. Detection rate of colorectal adenoma or cancer in unselected colonoscopy patients: Indonesian experience in a private hospital. Asian Pac J Canc Prev. 2014:9801-4.

12. Uçkmack F, Tuncer ET, Ekin N, Büyükbaryam H, Kaya M. Incidence and characteristics of colon polyps in Southeast Anatolian Region: A 5-year evaluation.2016.Turk J Colorectal Dis.p.21-6.
13. Levine JS, Ahnen DJ. Adenomatous polyps of the colon. $\mathrm{N}$ Engl $\mathrm{J}$ Med. 2006;355:2551-7.

14. Fick HS, Chahal G, Olomu A, et al. Colonic polyp histopathology in a community-based sample older adults. [diunduh Agustus 2016]. Tersedia dari: http://www.biomedcentral.com/bmcgastro enterol/.

15. Grahn SW, Varma MG. Factors that increase risk of colon polyps. Clin Colon Rectal Surg. 2008;21:247-55.

16. Delavari A, Mardan F, Salimzadeh H, Bishehsari F, Khozravi P, Khanehzad M, et al. Characteristics of colorectal polyps and cancer: a retrospective review of colonoscopy data in Iran. 2014. Middle East J Dig Dis. p.144-50.

17. Patel K, Hoffman NE. The anatomical distribution of colorectal polyps at colonoscopy. J Clin Gastroenterol. 2001:222-5

18. Qumseya BJ, Coe S, Wallace MB. The effect of polyp location and patient gender on the presence of dysplasia in colonic polyps. Am J Gastroenterol. 2012.p.1-5

19. Zauber AG, Winawer SJ, O'Brien MJ, Lansdorp-Vogelaar I, Ballegooijen MV, Hankey BF, Shi W, et al. Colonoscopic polypectomy and long-term prevention of colorectal-cancer deaths. N Eng J Med. 2012:687-96.

20. Chopra S, Cheng-wu ML. Specimens from biopsies of colorectal polyps often harbor additional diagnoses. Pathol Res Inter. 2013:1-6 